\title{
PENGARUH BRAND AWARENESS, BRAND IMAGE DAN CUSTOMER PERCEIVED VALUE TERHADAP PURCHASE INTENTION
}

\author{
Luki Lukmanul Hakim \\ Program Studi Magister Manajemen Universitas Tarumanagara \\ lukilukmanulhakim410@gmail.com \\ Keni \\ Program Studi Magister Manajemen Univeristas Tarumanagara
}

Masuk : 05-12-2019, revisi : 20-12-2019 diterima untuk diterbitkan : 21-12-2019

\begin{abstract}
This study aims to determine the effect of brand awareness, brand image, and customer perceived value on purchase intentions. The sampling technique used in this study is nonprobability sampling by purposive sampling using a quantitative approach by distributing questionnaires to 146 which valid respondents 142 respondents. Data analysis method used in this study is multiple regression analysis. For operational variables using the Likert scale method of validity used a computer measuring instrument that is SPSS 25.0. The results showed that the brand awareness variable have a significant and positif effect, brand image have a significant and positif effect, customer perceived value have a significant and positif effect on purchase intention. In this case the brand image is the most influences of purchase intention.
\end{abstract}

Abstrak : Penelitian ini bertujuan untuk mengetahui pengaruh brand awareness, brand image, dan customer perceived value terhadap purchase intention. Teknik pengambilan sampel digunakan pada penelitian ini adalah nonprobability sampling dengan cara purposive sampling dengan menggunakan pendekatan kuantitatif dengan menyebarkan kuesioner kepada 146 responden yang valid 142 responden. Metode analisis data yang digunakan dalam penelitian ini adalah analisis regeresi berganda. Untuk operasional variabel menggunakan metode skala Likert validitas digunakan alat ukur komputer yaitu SPSS 25.0. Hasil penelitian menunjukkan bahwa variabel brand awareness positif signifikan, brand image positif signifikan, customer perceived value positif signifikan terhadap purchase intention. Dalam kasus ini brand image yang paling berpengaruh terhadap purchase intention.

Kata Kunci : Brand Awareness, Brand Image, Customer Perceived Value, Purchase Intention

\section{PENDAHULUAN}

Perjalanan perangkat elektronik khususnya di bidang telekomunikasi terlihat jelas semakin berkembang pesat. Di Indonesia dimulai pada tahun 1993 PT Telkom yang mulai bergerak dengan proyek teknologi GSM hingga pada akhir 2015 4G masuk ke Indonesia. Setelah mengalami masa perkembangan jaringan telekomunikasi, barulah berbagai macam dan model ponsel mulai merangsek masuk ke pasar Indonesia dengan mengikuti perkembangan operator-operator dalam negeri. Pengguna smartphone di Indonesia telah tumbuh antara 30 persen hingga 50 persen setiap tahunnya (eMarketeer, 2016). Jumlah ini akan terus bertambah seiring pesatnya produk ponsel $4 \mathrm{G}$ dan jaringan $4 \mathrm{G}$ yang dikembangkan Indonesia. Pesatnya pengguna smartphone ini didukung oleh gaya hidup di daerah perkotaan (EMarketeer, 2016). Pelanggan menjadi target utama keberhasilan bisnis karena pelanggan menjadi sumber pendapatan perusahaan. Sehubungan dengan hal tersebut minat beli pelanggan adalah hal yang sangat penting untuk diperhatikan. Menurut Kotler (2016) purchase intention adalah perilaku konsumen ketika konsumen dirangsang oleh faktor-faktor eksternal dan memutuskan 
pembelian berdasarkan karakteristik pribadi masing-masing dan proses pengambilan keputusannya.

Purchase intention dipengaruhi beberapa faktor. Menurut Macdonald dan Sharp (2000) purchase intention dipengaruhi oleh variabel brand awareness dan mempunyai hubungan yang positif terhadap purchase intention. Fianto et al (2014) menemukan bahwa brand image secara signifikan mempengaruhi purchase intention. Faktor lainnya yang mempengaruhi purchase intention adalah customer perceived value. Menurut Isabelle dan Eluiza (2018) mendefinisikan "Perceived value involves a general assessment made by the consumer regarding the utility of a product or service, based on the perceptions of what is received and what is paid for". Tujuan penelitian ini untuk mengetahui pengaruh brand awareness, brand image, dan customer perceived value terhadap purchase intention. Hasil penelitian ini diharapkan agar perusahaan harus terus memperhatikan faktor brand awareness, brand image dan customer purchase value dalam kegiatan operasional perusahaan. Hal itu dikarenakan ketiga faktor tersebut sudah teridentifikasi sangat berpotensi menciptakan keputusan pelanggan yang akan meningkatkan purchase intention.

\section{TELAAH KEPUSTAKAAN \\ Brand Awareness}

Definisi brand awareness menurut Kotler (2016: 20) "brand awareness as fostering people's ability to recall or recognize the brand in sufficient detail to make a purchase". Dalam hal ini peneliti mendefinisikan brand awareness adalah kesanggupan pembeli untuk mengenali atau mengingat kembali ciri khas suatu merek. Menurut penelitian Macdonald dan Sharp (2000) mengemukakan bahwa brand awareness memiliki hubungan yang positif terhadap minat pembelian.

\section{Brand Image}

Keller (1993: 4) mendefinisikan "the brand image is the perception of a product which is a reflection of customers' memory in the product.". Jadi brand image adalah sebagai sebuah persepsi dari suatu produk yang merupakan cerminan dari memori pelanggan terhadap produk tersebut. Penelitian menurut Fianto et al. (2014) menemukan bahwa brand image secara signifikan mempengaruhi purchase intention. Brand image yang dikelola dengan baik akan menghasilkan efek yang positif dengan meningkatkan pengetahuan tentang aspek perilaku pelanggan dalam pembuatan keputusan

\section{Customer Perceived Value}

Menurut Zeithaml (1988: 5) mendefinisikan "Perceived value involves a general assessment made by the consumer regarding the utility of a product or service, based on the perceptions of what is received and what is paid for". Dalam hal ini peneliti berpendapat bahwa customer perceived value adalah sebagai berapa banyak nilai yang disediakan suatu produk atau layanan yang ada dalam benak konsumen. Isabelle dan Eluiza (2018) mengatakan customer perceived value berpengaruh positif terhadap purchase intention.

\section{Purchase Intention}

Menurut Kotler dan Keller (2016: 198) "purchase intention is a form of behavior from consumers who wish to buy or choose products based on experience, its use and desire in a product". Peneliti menilai purchase intention adalah tindakan dari konsumen untuk membeli suatu produk yang timbul dari dorongan dalam diri untuk memenuhi kebutuhan pribadinya.

\section{Kaitan antar Variabel \\ Pengaruh Brand Awareness Terhadap Purchase Intention}

Menurut penelitian Macdonald dan Sharp (2000) mengemukakan bahwa brand awareness memiliki hubungan yang positif terhadap minat pembelian. Brand awareness sangat berpengaruh kepada keputusan konsumen untuk membeli barang/jasa yang sudah familiar dan biasa dibeli sebelumnya. Lebih lanjut menurut Sharifi (2014) mengemukakan bahwa brand 
awareness memiliki hubungan positif terhadap purchase intention, dan juga dalam penelitian ini mengatakan bahwa brand awareness merupakan salah satu variabel penting dalam meningkatkan purchase intention.

Dalam penelitian Shahid, Hussain, dan Zafar (2017) menemukan bahwa variabel brand awareness memiliki pengaruh positif terhadap purchase intention. Ketika konsumen akan membeli sesuatu, konsumen akan lebih memilih untuk membeli brand yang sudah dia ketahui sebelumnya. Konsumen selalu ragu membeli produk dengan brand baru.

Berdasarkan pernyataan diatas, maka hipotesis penelitian adalah sebagai berikut:

$\mathrm{H}_{1} \quad$ : Terdapat pengaruh positif brand awareness terhadap purchase intention.

\section{Pengaruh Brand Image Terhadap Purchase Intention}

Penelitian menurut Fianto et al. (2014) menemukan bahwa brand image secara signifikan mempengaruhi purchase intention. Image dari sebuah brand adalah persepsi perlanggan terhadap sebuah brand seperti yang terlihat dari asosiasi brand yang sudah ada di dalam benak pelanggan. Brand image yang dikelola dengan baik akan menghasilkan efek yang positif dengan meningkatkan pengetahuan tentang aspek perilaku pelanggan dalam pembuatan keputusan. Dalam penelitian Rindell et al. (2011) menemukan bahwa brand image terbukti memiliki pengaruh positif dan signifikan terharap purchase intention.

Hasil penelitian Lien (2015) menunjukkan purchase intention dipengaruhi oleh brand image. Semakin tinggi brand image, semakin tinggi niat untuk membeli. Brand image yang tinggi memiliki pengaruh yang paling positif terhadap purchase intention dibandingkan dengan variabel lainnya seperti penelitian yang dilakukan oleh Manorek (2016), bahwa ada keterkaitan antara brand image yang tinggi dengan purchase intention.

Berdasarkan pernyataan diatas, maka hipotesis penelitian adalah sebagai berikut:

$\mathrm{H}_{2} \quad$ : Terdapat pengaruh positif brand image terhadap purchase intention.

\section{Pengaruh Customer Perceived Value Terhadap Purchase Intention}

Menurut penelitian yang dilakukan Hsinkuang et al. (2017) perceived value memiliki hubungan positif terhadap purchase intention. Model ini menunjukan bahwa perceived value yang tinggi akan meningkatkan niat beli yang tinggi. Dalam hal ini, konsumen dapat memperoleh perceived value yang dapat dipercaya yang dirasakan melalui rekomendasi dan dukungan pengiklan dan oleh karena itu perusahaan dapat meningkatkan daya saingnya. Serupa dengan penelitian tersebut, penelitian oleh Isabelle dan Eluiza. (2018) menemukan bahwa secara keseluruhan perceived value memiliki hubungan positif yang signifikan pada purchase intention secara keseluruhan. Dan juga customer perceived value merupakan variable yang penting dalam meningkatkan purchase intention.

Berdasarkan pernyataan diatas, maka hipotesis penelitian adalah sebagai berikut:

$\mathrm{H}_{3} \quad$ : Terdapat pengaruh positif customer perceived value terhadap purchase intention

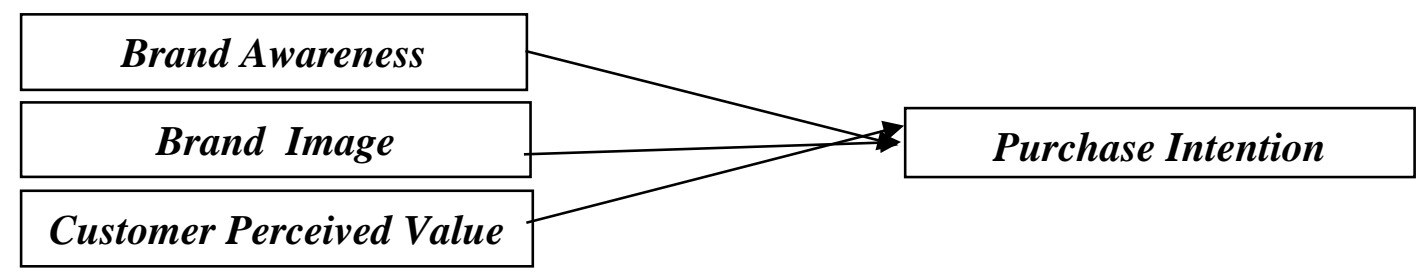

\section{METODOLOGI PENELITIAN}

Populasi dalam penelitian ini adalah orang yang mempunyai smartphone di Jakarta. Dengan sampel penelitian adalah 140 orang. Metode pengambilan sampel yang digunakan nonprobability sampling dengan purposive sampling. Berdasarkan data yang terkumpul, mayoritas karakteristik responden pada penelitian ini adalah pria (69\%), berusian $21-30$ tahun $(84,5 \%)$ 
dengan pendidikan terakhir mayoritas adalah S1 $(73,9 \%)$ yang berpenghasilan rata-rata $\mathrm{Rp}$. 2.000.000-9.000.000 (56,3\%).

Pada penelitian ini, variabel brand awareness, brand image, customer perceived value. merupakan variabel independent, sedangkan purchase intention adalah variabel dependent. Untuk mengukur variabel ini, menggunakan Skala Likert 5 poin dengan 1 menunjukan "sangat tidak setuju" dan 5 menunjukan "sangat setuju".

Metode analisis data yang digunakan adalah analisis regresi ganda. Sedangkan, untuk uji asumsi seperti uji normalitas, uji multikolinieritas dan uji heteroskedastisitas telah dilakukan sebelumnya dan hasilnya menunjukan semua uji asumsi sudah terpenuhi. Pengujian dalam penelitian ini menggunakan program SPSS 25.0. Taraf signifikansi yang digunakan dalam penelitian ini adalah 0,05 .

Tabel ini dibawah ini menunjukan pengukuran masing-masing variabel dan sumbernya:

Tabel 1. Variabel dan Pengukuran

\begin{tabular}{c|c|l}
\hline \multicolumn{1}{c|}{ Variabel } & Jumlah Item & \multicolumn{1}{|c}{ Sumber } \\
\hline Variabel Independent & & \\
1. Brand Awareness & 5 & Semuel, Setiawan (2018) \\
2. Brand Image & 5 & Lien et al. (2015) \\
3. Customer Perceived Value & 4 & \\
Performance/quality value & 4 & Sweeney dan Soutar's (2001) \\
$\quad$ Emotional Value Value of & 3 & \\
$\quad$ money / price & 4 & \\
$\quad$ Social Value & 4 & Busler (2000); Lin dan Lin (2007); \\
Variabel Dependent & & Jalilvand et al. (2011) \\
1. Purchase Intention & 5 & \\
\hline
\end{tabular}

\section{ANALISA DAN PEMBAHASAN}

Tabel 2. Hasil Pengujian Hipotesis

\begin{tabular}{|l|l|c|c|c|}
\hline & \multicolumn{1}{|c|}{ Hipotesis } & B & Sig & Kesimpulan \\
\hline H1 & $\begin{array}{l}\text { Terdapat pengaruh positif brand awareness } \\
\text { terhadap purchase intention. }\end{array}$ & 0,254 & 0,001 & Tidak Ditolak \\
\hline H2 & $\begin{array}{l}\text { Terdapat pengaruh positif brand image } \\
\text { terhadap purchase intention. }\end{array}$ & 0,257 & 0,001 & Tidak Ditolak \\
\hline H3 & $\begin{array}{l}\text { Terdapat pengaruh positif customer perceived } \\
\text { value terhadap purchase intention. }\end{array}$ & 0,132 & 0,000 & Tidak Ditolak \\
\hline
\end{tabular}

Berdasarkan hasil pengujian hipotesis pada model 1, maka dapat disimpulkan bahwa brand awareness, brand image, customer perceived value berpengaruh positif terhadap purchase intention. Ini berarti konsumen memiliki tingkat pembelian yang tinggi terhadap smartphone Huawei karena adanya kesadaran merek, citra merek, dan persepsi konsumen yang baik. Hipotesis H1 ini sesuai dengan penelitian Macdonald dan Sharp (2000) mengemukakan bahwa brand awareness memiliki hubungan yang positif terhadap minat pembelian. Ketika konsumen akan membeli sesuatu, konsumen akan lebih memilih untuk membeli brand yang sudah dia ketahui sebelumnya. Konsumen selalu ragu membeli produk dengan brand baru. Penulis dapat menyimpulkan pentingnya brand awareness terhadap mebangun minat beli. Selanjutnya Hipotesis H2 sesuai dengan Fianto et al. (2014) menemukan bahwa brand image secara signifikan mempengaruhi purchase intention. Brand image yang dikelola dengan baik akan menghasilkan efek yang positif dengan meningkatkan pengetahuan tentang aspek perilaku pelanggan dalam pembuatan keputusan. Kemudian untuk hipotesis H3 juga sudah 
sesuai dengan Isabelle dan Eluiza (2018) mengatakan customer perceived value berpengaruh positif terhadap purchase intention. konsumen akan membandingkan nilai produk / jasa tersebut apakah sudah sesuai atau tidak dengan persepsi mereka dan apakah juga sesuai dengan pengorbanan yang sudah konsumen keluarkan seperti biaya, waktu, jasa untuk membeli produk/jasa tersebut. Semakin banyak value yang dirasakan, konsumen akan melakukan pembelian lagi.

Dengan demikian maka seluruh hipotesis penelitian ini terbukti dengan adanya data secara empiris. Purchase intention dapat diprediksi oleh brand awareness, brand image, dan customer perceived value. Dengan demikian, maka dapat dilihat bahwa purchase intention dalam hal ini dapat dipengaruhi oleh kesadaran merek Huawei yang dirasakan pelanggan, citra merek Huawei yang baik, dan persepsi nilai yang dirasakan oleh pelanggan akan produk smartphone Huawei.

\section{KESIMPULAN DAN SARAN}

Kesimpulan. Dalam melakukan bisnis apapun, pelaku bisnis mengharapkan bisnis tersebut dapat bertahan lama. Salah satu faktor penting dalam mewujudkannya adalah membangun minat pembelian pelanggan. Tidak hanya mengandalkan kekuatan brand dan inovasi, tetapi perlu ada faktor lain. brand awareness, brand image, dan customer perceived value juga menjadi hal yang signifikan yang dapat berpengaruh terhadap keberlangsungan bisnis. Brand Awareness yang dimilik pelanggan membuat pelanggan lebih mudah dalam mengambil keputusan pembelian. Demikian dengan Brand Image, perusahaan yang membangun image yang baik akan mebuat minat beli konsumen meingkat produk dengan brand yang terkenal, adanya asumsi bahwa brand terkenal lebih dapat diandalkan, selalu tersedia dan mudah dicari, dan memiliki kualitas yang tidak diragukan. Begitu juga dengan customer perceived value, perceived value yang lebih tinggi membuat niat beli yang lebih tinggi semakin banyak value yang dirasakan, konsumen akan melakukan pembelian lagi.

Saran. Peneliti menyarankan agar perusahaan harus terus memperhatikan faktor brand awareness, brand image dan customer purchase value dalam kegiatan operasional Huawei. Hal itu dikarenakan ketiga faktor tersebut sudah teridentifikasi sangat berpotensi menciptakan keputusan pelanggan yang akan meningkatkan purchase intention smartphone.

\section{IMPLIKASI MANAJERIAL}

Berkaitan dengan hasil penelitian, maka dapat disampaikan beberapa implikasi manajerial yang bisa diterapkan oleh perusahaan. Peneliti menyarankan pentingnya marketing sebuah brand, bisa melalui media sosial. Melalui media sosial brand perusahaan bisa berinteraksi dengan para konsumen dan calon konsumen secara langsung. Dengan menciptakan brand experience dari pelanggan yang sesuai dengan dengan keinginan konsumen itu sendiri. peneliti juga menyarankan agar perusahaan harus dapat fokus ke target market yang dituju, sehingga perusahaan bisa melakukan inovasi yang tepat yang dibutuhkan oleh pelanggan. Sehingga bisa bersaing dengan brand lainnya, Peneliti juga menyarankan agar perusahaan dapat menunjukan fungsi dari produk secara maksimal. Ketika pelanggan mengetahui fungsi produk dengan maksimal, pelanggan akan rela melakukan pembelian ataupun membayar mahal harga produknya. 


\section{DAFTAR PUSTAKA}

EMarketeer (2016). Indonesia Is The $3^{\text {rd }}$ Largest Smartphone Market In The Asia Pacific Retrieved from Indonesia Investment: https://www.indonesiainvestments.com/news/todays-headlines/indonesia-is-the-3rd-largest-smartphonemarket-in-the-asia pacific/item6777 [Diakses pada Tanggal 25 November 2018].

Fianto, A.Y.A., Hadiwidjojo, D., \& Aisjah Siti (2014). The Influence of Brand Image on Purchase Behaviour Through Brand Trust. Journal of Business Management and Strategy, 5 (02), pp.58-76

Hsinkuang, C., Yeh, H.R., \& Tsai, Y.C (2017) The Influences of Perceived Value on Consumer Purchase Intention: The Moderating Effect of Advertising Endorser. International Journal of Marketing Studies, 7 (6).

Isabelle, C.G.C., Eluiza, A.M.W., \& Alfinito, S. (2018). Purchase intention of organic food under the influence of attributes, consumer trust and perceived value. Revista de Gestão 26 (3) pp. 198-211

Jalilvand, M, R., Samiei, N., \& Mahdavinia, S, H. (2011). "The effect of brand equity components on purchase intention", International business and management, 2(2), pp. 149-158.

Keller, K. L. (1993). Conceptualizing, Measuring and Managing Customer-Based Brand Equity. Journal of Marketing, 57(1), pp 1-22

Kotler, P., \& Keller, L. (2016). Marketing Management $15^{\text {th }}$ edition. New Jersey : Pretince Hall.

Lien, C. H., Wen, M.J., Huang, L.C., \& Wu, K.L (20015). Online hotel booking: The effects of brand image, price, trust and value on purchase intentions. Asia Pacific Management Review, 20, pp. 210-218.

Lin, N. H., \& B.S Lin (2007). "The Effect of Brand Image and Product Knowledge on Purchase Intention Moderated by Price Discount". Journal of International Management Studies, 2 (13), pp. 121-132.

Macdonald, E. K., \& Sharp, B. M. (2000). Brand awareness effects on consumer decision making for a common, repeat purchase product: A replication. Journal of Business Research, 48, 5-15

Rindell, A., Korkman, O., \& Gummerus, J. (2011). The Role of Brand Images in Consumer Practices: Uncovering Embedded Brand Strength. Journal of Product \& Brand Management, 20(6), pp 440-446.

Semuel, H., \& Setiawan, K.Y. (2018). Promosi Melalui Sosial Media, Brand Awareness, Purchase Intention Pada Produk Sepatu Olahraga. Jurnal Manajemen Pemasaran, 12 (1), pp. 47-52

Shahid, Z., Hussain, T., \& Zafar, F. (2017). The impact of brand awareness on the consumers' purchase intention. Journal Account Marketing, 6(1), pp. 223-226

Sweeney, J.C., \& Soutar, G.N. (2001). Consumer perceived value: the development of a multiple item scale. Journal of Retailing, 77 (2), pp. 203-20.

Till, B. D., \& Busler, M. (2000). "The Match-up Hypothesis: Physical Attractiveness, Expertise, and the Role of Fit on Brand Attitude, Purchase Intent and Brand". Beliefs. Journal of Advertising, 29 (3), pp. 1-13.

Zeithaml, V. A. (1988). Consumer perceptions of price, quality, and value: a means-end model and synthesis of evidence. Journal of Marketing, 52 (3), pp 2-22. 